Submission ID: 43831

\title{
Developing a Unique Size 3D Geomechanics Model - Features and
}

\section{Advantages. East Siberia}

M. Lushev* (Gazprom geologorazvedka), E. Tryasin (Gazprom geologorazvedka), D. Maximov (Schlumberger), S. Kreknin (Gazprom geologorazvedka), V. Pavlov (Schlumberger), S. Strakhov (Schlumberger), E. Korelskiy (Schlumberger), A. Zinoviev (Schlumberger)

\section{SUMMARY}

In the context of developing the unique three-dimensional geomechanical model shows a number of a new technical solutions under conditions of extremely large size of the modeled area, without sacrificing high detailization of model which is sufficient to solve the problems of the construction and completion of wells in areas of exploration drilling.

First time in the world realized the development of a unique scale three-dimensional geomechanical model covering the entire contour of the field $-20,000 \mathrm{~km} 2$. The main stages of model development was reviewed based on the technical and geological characteristics of the modeled area to offer a unique solution. Analyzed the applicability of new technical solutions on the example of a particular field. 


\section{Построение уникальной трехмерной геомеханической модели Чаяндинского} месторождения, Восточная Сибирь

M.А. Лушев* (ООО “Газпромгеологоразведка"), Е.Ю. Трясин (ООО "Газпромгеологоразведка"), С.Г. Крекнин (ООО "Газпромгеологоразведка"), В.А. Павлов (“Шлюмберже Лодж. Инк.”), Е.П. Корельский (“Шлюмберже Лодж. Инк.”), А.А. Зиновьев (“Шлюмберже Лодж. Инк.”), Д.А. Максимов (“Шлюмберже Лодж. Инк.”), С.Г. Страхов (“Шлюмберже Лодж. Инк.”)

\section{Введение}

Чаяндинское нефтегазоконденсатное месторождение расположено на территории Ленского и частично Мирнинского улусов (районов) Республики Саха (Якутия), в 170 км западнее г. Ленска, в 240 км юго-западнее г. Мирный. В пределах Непско- Ботуобинской НГО в настоящее время разведано 13 месторождений нефти и газа, среди которых три крупных и одно уникальное. Главные нефтегазоносные объекты НГО - отложения рифей-венднижнекембрийского терригенно-карбонатного комплекса. Основные газовые залежи находятся в ботуобинском и хамакинском продуктивных горизонтах венда. Ботуобинский горизонт соответствует нижней подсвите бюкской свиты; хамакинский горизонт - верхней подсвите паршинской свиты $[1,2]$. Мощность тел достигает 20 м. Менее крупная залежь сосредоточена в породах талахского продуктивного горизонта, соответствующего талахской свите венда. Однако она распространена локально, только в центральных частях месторождения. Коллектор терригенный. Все залежи пластовые, литологически и тектонически экранированные. Глубина залегания залежи - 1450 - 1850 м. Разрывные нарушения делят месторождение на два блока северный и южный [3], также на месторождении отмечено значительное число более мелких нарушений. Терригенные залежи характеризуются аномально низкими пластовыми давлениями, а покрывающие глины низкими прочностными свойствами, недостаточными для поддержания стабильности горизонтальных стволов. На момент начала работ по моделированию на месторождении пробурено около 150 вертикальных и 20 наклонных/горизонтальных скважин (в разных частях месторождениях при различных вертикалях продуктивных горизонтов). При бурении наклонных скважин отмечено значительное число осложнений, в том числе потеря компоновок и забурка боковых стволов. Запись каротажей проводилось в различное время и различными подрядчиками, поэтому данные имеют различное качество и не были отнормированы, значительное влияние на качество данных ГИС также оказывают большие обрушения в глинистых интервалах. Большая площадь месторождения 110 *180км ведет к необходимости использования ячеек значительных размеров (1км*1км), при использование численного моделирования, что недопустимо - при необходимости использования результатов моделирования для оптимизации горизонтальных скважин, так как весь участок горизонтального ствола фактически будет попадать в одну ячейку. Необходимость создания трехмерной геомеханической модели Чаяндинского месторождения в первую очередь для получения величины «безопасного окна бурения» эксплуатационных скважин, с учетом выше описанных особенностей привела к необходимости выработки нестандартных решений при моделировании.

\section{Использованные подходы}

Информация по полученным осложнениям является критичной для инженеров-геомехаников, в первую очередь для определения интервалов осложнений, во вторую очередь для выявления истинных причин полученных проблем. При этом стандартный анализ осложнений при аудите данных бурения предполагает построение двух типов диаграмм, с нанесением на них осложнений: глубина - время; по глубине. Очевидно, что построение таких картин является, наиболее, удобным для определения механизмов возникновения проблем и процедур, при которых были эти проблемы получены. Также, данные диаграммы позволяют косвенно оценить стабильность ствола скважины с течением времени. Однако, при наличии на месторождении значительного количества скважин, а тем более вариативности литологии и 
отсутствии латеральной выдержанности пластов - Рис. 26 данный анализ не позволяет выделить общие причины и интервалы осложнений для всех скважин. Предложенный анализ, заключающийся в отображении осложнений на плот-диаграммах с фиксацией зенитного угла и азимута места осложнения, применим при наличии на месторождении истории бурения наклонно-направленных или горизонтальных скважин. Диаграмма на Рис.1а позволяет определить не только направление появления осложнений, но также позволяет оценить критическую величину угла вскрытия пласта, при достижении которой происходили эти осложнения. Предлагаемый алгоритм также позволяет определить азимут бурения скважин, в направлении которого присутствует преобладающий тип осложнения.

Разбуривание уникальных месторождений разведочными скважинами связано со значительными временными затратами и как правило занимает несколько десятилетий, за которые геофизическая аппаратура успевает усовершенствоваться и значительно измениться качество получаемых данных, более того запись каротажа различными сервисными компаниями часто ведет к отсутствию единой увязки и нормализации данных ГИС по месторождению. На примере Чаяндинского месторождения эта проблема дополнительно осложнена наличием протяженных глинистых интервалов значительного обвалообразования, где данные получаемого акустического и плотностного каротажа чаще всего сомнительного качества - Рис 1б. Для создания полноценной 3D геомеханической модели необходимо распространение скважинных каротажей в межскважинное пространство. Для распространения каротажей чаще всего используются способы геостатистики с различными методиками распространения данных. При этом для корректного распространения каротажей необходимо использовать подложку для их экстраполяции в межскважинном пространстве (например акустический импеданс, пористость, глинистость). В случае наличия значительных вариаций в ГИС на скважинах выходная модель будет иметь «пятна» характеризующие изменения свойств, хотя в действительности они связанны с ошибками в интерпретации логов. Так как основой создания механических свойств в межскважинном пространстве и в модели в целом служат данные записи каротажей, процесс оценки качества данных ГИС используемых при моделировании (плотности, продольной и поперечной акустической волны) в рамках $3 \mathrm{D}$ моделирования представляет важную и необходимую задачу. Так, основными задачами при оценке качества служит: определение качества записанных ГИС, устранения интервалов некачественной записи (ввиду вывалов скважин, влияния приборов и т.д.), определение латеральной выдержанности значений между скважинами (отсутствие заведомо завышенных или заниженных значений по всему стволу). Проведение сдвига данных на основании приведения величин скорости пробега в реперных толщах к заданным величинам позволяет избежать проблем связанных с образованием зон неоднородностей при моделировании.
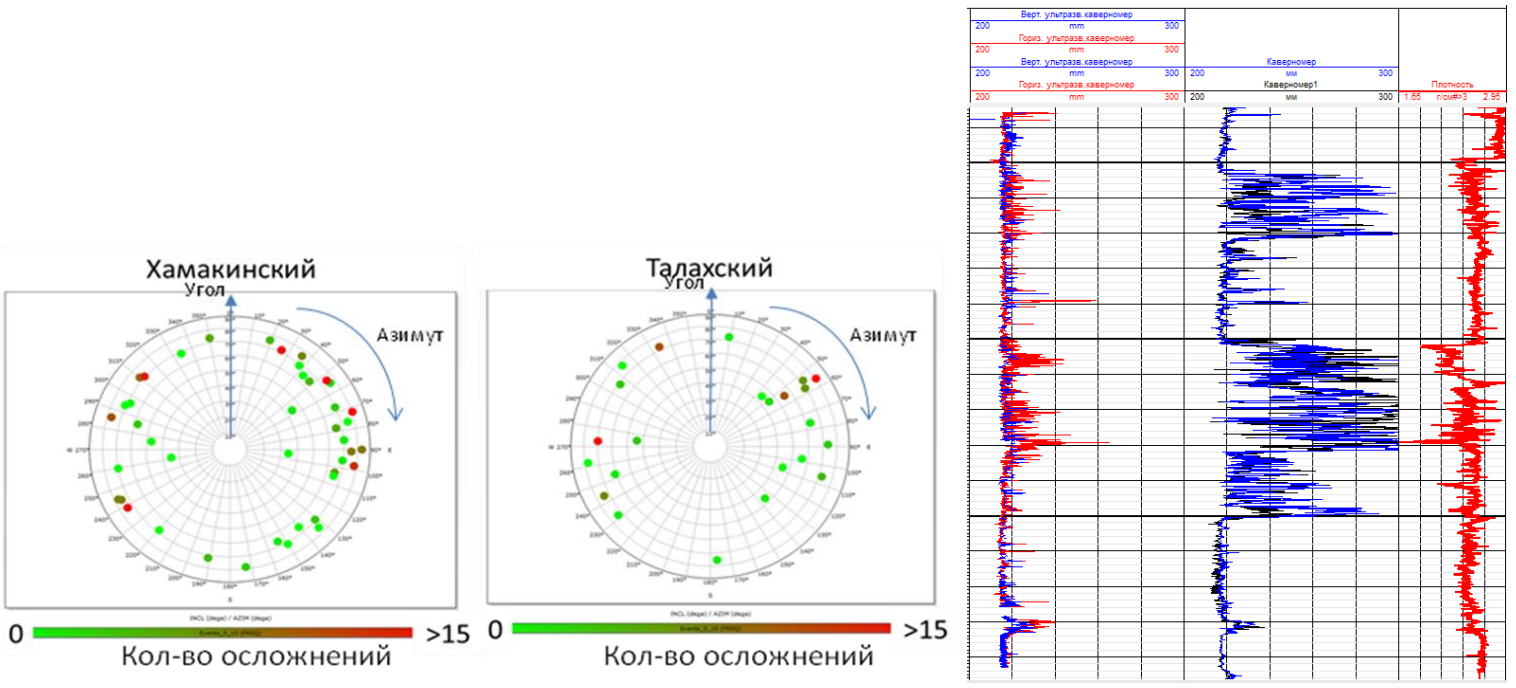

Рисунок 1 Количество осложнений при бурении на различные горизонты при различных зенитных углах вскрытия и азимутах (а), изменения диаметра скважины со временем, во 
время бурения - трек 1, при записи на кабеле -трек 2, влияние обвалообразования на плотность - трек 3 .

Последним решением, связанным с необходимостью увеличения разрешения модели в районе активного разбуривания при сохранении общего числа ячеек в разумных пределах было создание локальной измельченной сетки в центральной части месторождения, это позволило уменьшить размер ячеек в данной области с $1 * 1$ км до $200 * 200$ м при общем увеличении числа ячеек модели в два раза, при этом использование ячеек размером $200 * 200$ м по всему месторождению привело бы к увеличению числа ячеек в двадцать пять раз. Однако для использования всех преимуществ получаемых при локальном измельчении сетки в определенном районе очевидно необходима подача в геомеханическую модель исходных данных с таким же размером ячеек как в измельченной модели. Кроме того использование измельченной сетки позволило более детально исследовать поведение приразломных зон на напряженно-деформированное состояние массива. Полученные результаты верифицировались на реально полученные данные по изменению ориентации поля напряжений в приразломных зонах по данным скважинных имиджей и снижению напряжений по данным о поглощениях в скважинах, при бурении через зоны тектонических нарушений.
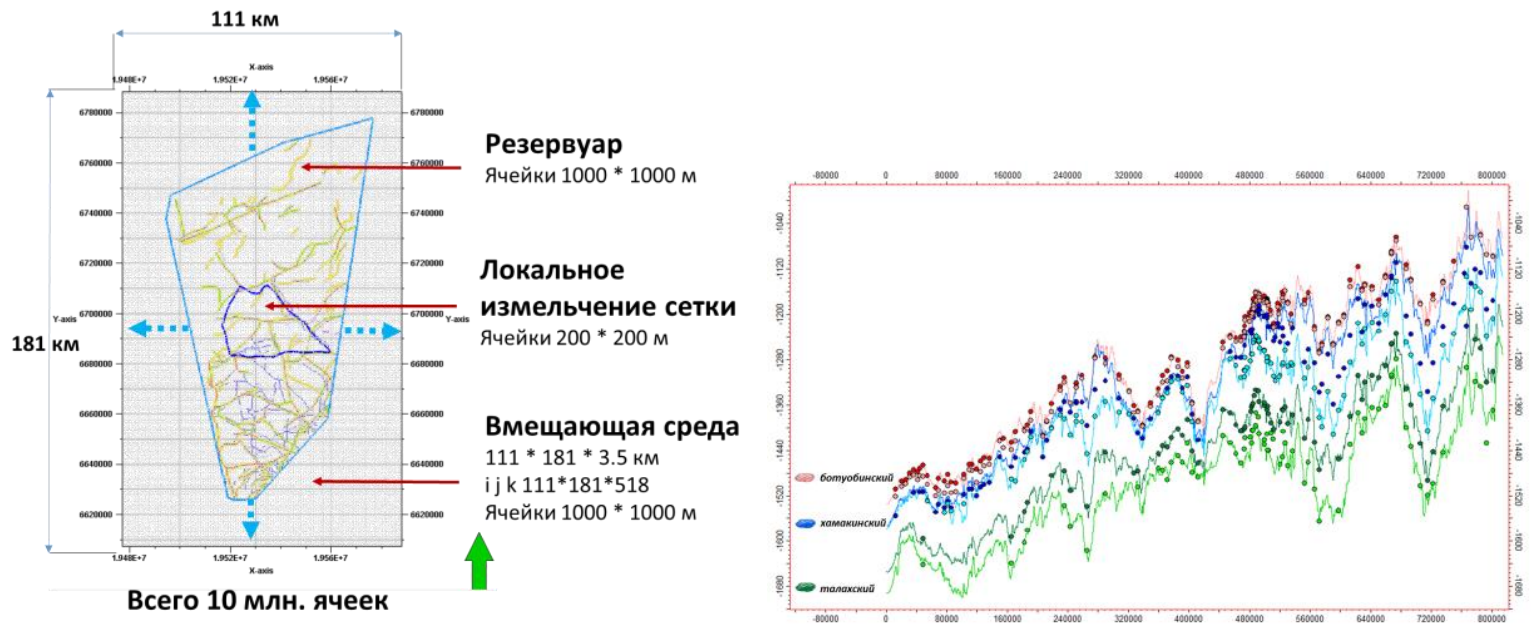

Рисунок 2 Особенности построенной модели: значительная площадь модели и число ячеек с использованием локального измельчения в районе активного бурения (a), изменение глубиньы залегания продуктивных горизонтов по латерали составляет 300-500м (б)

\section{Полученные результаты}

Подходы анализа данных о бурении и осложнениях позволили сформировать полное представление о зонах осложнений, получаемых проблемах и наиболее вероятных причинах их происхождения - обвалообразование (нестабильность стенок скважины), построение карт регионального распределение осложнений позволило определить, что осложнения не привязаны к определенным зонам (например, тектонических нарушений) равномерно распределены по площади месторождения, следовательно нестабильность ствола вызвана невозможностью поддержания стенок скважины в стабильном состоянии при определенных углах, даже при использовании значительного веса бурового раствора, так как его увеличение вело к повышению риска поглощений в продуктивных зонах с аномально низкими пластовыми давлениями. Используя предложенные выше решения для условий Чаяндинского месторождения, построена полноразмерная геомеханическая модель, включающее все месторождение. Размеры модели 180*110км с общим числом ячеек 19млн. - Рис.2а, с учетом локального измельчения сетки в центральной области месторождения. Проведенная нормировка исходных данных ГИС позволила получить качественные входные данные для распространения свойств в межскважинное пространство с отсутствием зон явных 
неоднородностей вызванных неточностью записи ГИС, невнесением поправок или влиянием обрушений на качество каротажа. Локальное измельчение сетки в районе активного эксплуатационного бурения позволил построить геомеханическую трехмерную модель уникального Чаяндинского месторождения - Рис.3, без значительного увеличения числа ячеек и временных затрат на проведения расчетов при увеличении латерального разрешения моделирования достаточного для построения моделей устойчивости горизонтальных эксплуатационных скважин.

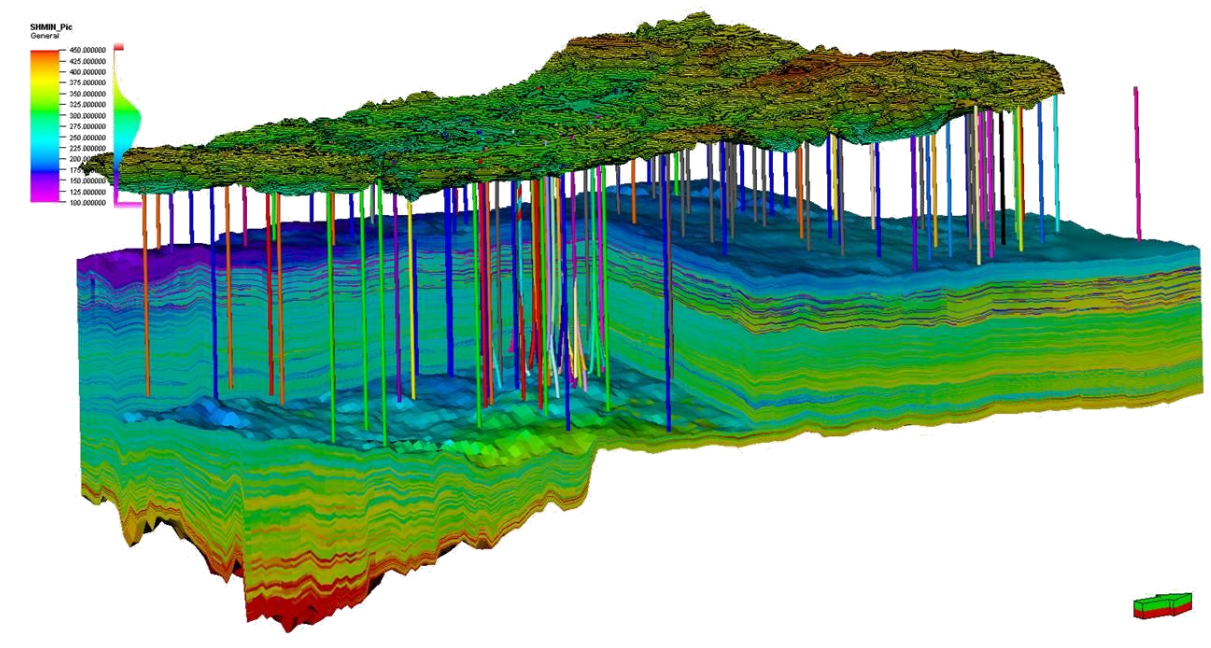

Рисунок 3 Минимальные горизонтальные напряжения с отображенными пробуренными скважинами и структурной картой земной поверхности.

\section{Заключение}

Используя предложенные подходы определены интервалы наибольших осложнений, возникающих при бурении и их причины - нестабильность стенок ствола скважины глинистые интервалы над продуктивными горизонтами, определены критические углы вскрытия этих глин и оптимальные углы и азимуты для снижения рисков связанных с геомеханикой. Алгоритм нормализации входных данных ГИС позволил получить качественные кубы механических свойств для построения полноценной геомеханической модели. Локальное измельчение сетки в районе активного эксплуатационного бурения позволил построить геомеханическую трехмерную модель уникального Чаяндинского месторождения без значительного увеличения числа ячеек и временных затрат на проведения расчетов при увеличении латерального разрешения моделирования достаточного для построения моделей устойчивости горизонтальных эксплуатационных скважин. Включение тектонических нарушений в геомеханическую модель позволило определить величину их влияния на напряженно-деформированное состояние массива и риски при бурении скважин.

\section{Библиография}

1. Крекнин С.Г., Погрецкий А.В., Крылов Д.Н., Трухин В.Ю., Ситдиков Н.Р. Современная геолого- геофизическая модель Чаяндинского нефтегазоконденсатного месторождения. Геология нефти и газа, №2, 2016г.

2. Конторович В.А., Моисеев С.А., Скузоватов М.Ю., Следина А.С. Сейсмологическая модель строения терригенных отложений венда центральных районов непско-ботуобинской антеклизы. Геология нефти и газа, №1, 2009г.

3. Рыжков А.Е., Крикунов А.И., Филиппова Л.А., Канунникова Н.Ю., Саприна О.А. Определение степени влияния тектонического фактора на формирования залежей углеводородов на Саманчакитском блоке Чаяндинского нефтегазоконденстаного месторождения. Вести газовой науки, №3 (19), 2014г. 


\section{References}

1. Kreknin S.G., Pogreckiy A.V., Krylov D.N., Trukhin V.U., Sitdikov N.R. Modern geological and geophysical model of Chayandinskoye oilfield. Oil and Gas Geology №2, 2016.

2. Kontorovich V.A, Moiseyev S.A, Skuzovatov M.Yu., Slegina A.S. Seismological model of Vendian reservoir terrigenous structure in central Nepa-Botuobin anteclise regions. Oil and Gas Geology, № 1, 2009.

3. Ryzhkov A.E, Krikunov A.I, Filippova L.A, Kanunnikova N.Yu. Saprina O.A. Determination of the tectonic factor influence on the hydrocarbon reservoirs formation within Samanchakit block of the Chayandinskoye oil and gas condensate field. News of gas science, №3 (19), 2014. 